\title{
REPORTS OF COMMITTEES
}

Report of the Committee of the American Astronomical Society on the merits of the proposed international project of determining accurate proper motions with the Photographic Zenith Tube.

I. The experience in Washington has demonstrated the excellent opportunity that the use of photographic zenith telescopes presents for obtaining absolute proper motions in declination. Even without transit observations, periodic errors in right ascension, not only in proper motion but also in position, can be eliminated. In right ascension possible periodic errors in position will be eliminated by smoothing the places, and time determinations with the P.Z.T. can be compared with time based directly on clock stars. By transit observations, the P.Z.T. stars are eventually tied in to a well defined system of clock stars and thereby absolute proper motions are also obtained in right ascension. On the basis of their results, the Washington observers conclude that, in about ro years, proper motions can in this way be obtained that have smaller accidental and smaller systematic errors than are now found in Catalogue proper motions.

The principal limitation of the instrument is that only stars in a $20^{\prime}$ belt, culminating near the zenith, are accessible to observation. If, however, a number of stations in widely different latitudes, both north and south of the equator, were established, the resulting proper motion material covering separate strips of declination would go a long way in smoothing out the periodic errors over the entire sky and would be of great value for the study of the motions in the galactic system. Even at $\mathrm{O}^{\mathrm{h}}$ and $\mathrm{I} 2^{\mathrm{h}}$ it takes 60 years to carry a star completely across a $2 \mathrm{O}^{\prime}$ field, and this certainly gives an ample interval for proper motions.

By using the necessary precision clocks and radio receiving and sending apparatus, the equipment may also be used for time determination, as has been demonstrated at Washington.

2. The Photographic Zenith Tube of the U.S. Naval Observatory has proved so successful an instrument that various other observatories are now considering a similar installation; in particular, construction is far advanced for the Royal Observatory, Greenwich (new site). The U.S. Naval Observatory has decided on a second instrument, possibly to be located in Cuba. In addition to these three instruments for Greenwich and Washington, interest has been expressed in four more. The Commonwealth Solar Observatory, Mount Stromlo, Canberra, Australia, proposed in October 1944 to erect a P.Z.T. as part of a scheme for establishing a Commonwealth Time Service. During 1945 Representatives of the Brazilian Navy and the Argentine Navy inquired about the P.Z.T. and word has just been received at Washington that Delporte wishes one. for Uccle. All of these are in connection with time service installations.

3. Three different types of station may be envisaged:

I. Stations with complete time equipment including precision clocks and radio sending and receiving apparatus.

(p.m. in right ascension and declination, time service.)

II. Stations with minimum equipment for time determination consisting of a precision clock and chronograph and radio receiving set.

(p.m. in right ascension and declination.)

III. Stations without equipment for time determination and right ascension work. (only p.m. in declination and variation of latitude.)

4. The variation of latitude could be covered in a variety of ways, and not only by stations on the same parallel. However, the advantage that the same stars can be used seems to favor a distribution like the present one, and it should be urged that the existing latitude stations on the parallel $39^{\circ} 8^{\prime}$ north at Ukiah, California, Carloforte, Italy, Kitab, U.S.S.R. and Gaithersburg, Maryland be equipped with P.Z.T.'s. A fourth existing station at Mizusawa, Japan should perhaps be taken into account. These stations, being only $\mathrm{I} 3$ ' north of Washington, would not have to be equipped with precision clocks and could be entirely devoted to the latitude service as they are now. It has also been mentioned that it might be more economical to abandon Gaithersburg and move the other two I $3^{\prime}$ south (Clemence).

5. Mention should be made of the suggestion (Atkinson) that, with the greatly improved technique of chronographing radio time signals, time determination may soon provide an independent 
check on the displacements of the pole. For this purpose, it would be desirable to have pairs of fully equipped stations in the same longitude but in widely different latitudes. They should simultaneously send and receive on approximately the same wave length so that variations in effective path will cancel out. The Y component of the polar motion must cause the difference between Greenwich and Capetown to vary over a total range of about 30 milliseconds. Another such pair could be formed between Washington and Cordoba, La Plata or Montevideo, and possibly a third between Japan (Mizusawa) or eastern Siberia and Melbourne or Wellington.

6. Consideration has been given to the best lenses to be used for P.Z.T. The field at Washington is $20^{\prime}$. The Greenwich tube is to have $30^{\prime}$. At the equator, the field could probably be still more. The Washington people believe that the focal length should not be cut down below I2 feet (their instrument has I6 feet with an opening of 8 inches). It is possible that even in the zenith, the seeing would be better in the red than in the blue. Work in the red would, with the present fast plates, not mean a serious loss of stars. One should make sure, however, that the use of a filter would not introduce a greater loss in accuracy than would be gained by the better seeing.

7. As to the location: if the seven stations mentioned in (2) should all come in to being, the approximate latitudes would probably be $+5^{\circ}$, $+51^{\circ},+39^{\circ},+20^{\circ},-22^{\circ},-35^{\circ},-35^{\circ}$. Greenwich and Belgium, and Argentina and Australia might thus overlap each other. It would be better to have these instruments on different parallels about $10^{\circ}$ apart. With a view to the requirements of the proper motion work, the time work, and the pole determination, about ten fully equipped stations supplemented by about two or three partial stations could, if reasonably distributed, take care of the entire project. (This would be not counting the three latitude stations on the $+39^{\circ} 8^{\prime}$ parallel.) If various stations separated by considerably less than $15^{\circ}$ of latitude were established, they would afford the means of a tie with proper motions of stars obtained by observations with wide-angle cameras. This Committee does not, at the present time, submit a tentative list of proposed stations because it seems better to leave this open until the various national committees have had an opportunity to indicate their interests.

8. Finally, about the actual organizational aspect: There seems no doubt that here is an opportunity to inaugurate an important piece of cooperative endeavor between many nations. The participating institutions can work practically independently, each making valuable contributions by itself, and gradually, at the same time, contributing to a common goal.

Our Committee recommends that the Executive Committee of the I.A.U., after examining the project, bring it to the attention of the national committees of the member countries with such recommendations as they see fit. It is felt that, whereas the relation of the present plan to the International Latitude Service and to the Bureau de l'Heure will have to be considered, the Executive Committee itself is probably the only body which can come to any well informed conclusion on this subject. It is further recommended that the Executive Committee consider the desirability of setting up an information center, to which all interested parties could contribute their views and which could then arrange to circulate them.

$$
\begin{aligned}
& \text { R. d'E. Atkinson } \\
& \text { Dirk Brouwer } \\
& \text { Gerald M. Clemence } \\
& \text { W. J. Eckert } \\
& \text { Paul Sollenberger } \\
& \text { Jan Schilt, Chairman }
\end{aligned}
$$

Appendix A: letter from the Superintendent, United States Naval Observatory to the General Secretary, International Astronomical Union.

\section{Dear Dr. Oort:}

I9 December I945.

The determination of absolute proper motions, or what is nearly the same, the correction of the systematic errors in star catalogues, is one of the most important problems in astronomy. Two independent methods of attack on this problem have recently been proposed. One of these utilizes the reference frame provided by the motions of certain minor planets, the other the extra-galactic nebulae. A third independent method, proposed by Dr. Jan Schilt, is made possible by the high accuracy with which absolute proper motions can be determined with the photographic zenith tube. Experience at Washington has indicated that with one of these instruments absolute proper motions in declination and relative motions in right ascension can be obtained in ten years with an accuracy exceeding that furnished by all previous observations. The zenith tube is limited to 
a narrow zone of declination, but a sufficient number of instruments well spaced in latitude, perhaps at intervals of Io degrees, will suffice to lay the groundwork for a system which can be extended over the whole sky by means of existing catalogues and observations with transit circles.

It is recommended that the International Astronomical Union give consideration to sponsoring such a program. One instrument on each chosen parallel of latitude would suffice, with two exceptions; on each of two parallels suitably chosen north and south there should be three instruments for the purpose of determining the polar motion. A clock of the highest precision would be needed for each instrument. In addition to accomplishing the main purpose, the polar motion and the time would be determined with an accuracy hitherto not possible. The absolute latitudes and longitudes of the several stations would be determined by the transit circle observations at existing locations.

The zenith tube at Washington, another shortly to be constructed by the Naval Observatory, and the one soon to be placed in service at Greenwich, will provide three links in the chain. Further links can conveniently be provided by superseding the equipment now in use at the several stations of the latitude service. The Naval Observatory would support the program in every way possible, and would undertake to keep the star lists north of declination $30^{\circ}$ south continuously under observation with its transit circles.

\section{Sincerely yours, (signed) J. F. Hellweg}

Appendix B: action taken by the Executive Committee of the International Astronomical Union.

To Presidents of National Committees of Astronomy

Dear Sir,

At the meeting of the Executive Committee of the International Astronomical Union at Copenhagen March 7-12 with representatives from various countries a plan was discussed concerning the possible erection of a number of photographic zenith-tubes, with a view to improving the system of stellar proper motions and the determination of latitude and longitude variations, as well as of time. The plan, which was originally suggested by Professor J. Schilt, was brought to our attention by Commodore Hellweg of the Naval
Observatory, Washington, while we have further received an extensive report from a special commission of the American Astronomical Society.

I am enclosing a copy of this report, as well as of Commodore Hellweg's letter concerning this project, for your consideration.

The Executive Committee warmly recommends the project to your attention, considering that the execution of such a plan will contribute greatly to our knowledge of the motion of the pole and of the Earth's crust, and improve the determination of time, while it will at the same time yield much needed absolute proper motions of a set of selected stars, which may become of particular value for fundamental investigations on the Galactic System.

It expresses the hope that your Committee may find it possible to promote in your country projects for the erection of zenith-telescopes of the type considered.

It is proposed to set up at the Naval Observatory, Washington, an information center for all matters concerning this plan. Correspondence on the plan should be addressed to the Superintendent, U. S. Naval Observatory, Washington, D. C., U.S.A.

\section{Yours truly, (signed) J. H. Oort, General Secretary, I.A.U.}

\section{A Report of the Panel on the orbits of eclipsing binaries.}

The Panel on the orbits of eclipsing binaries was formally instituted in April 1946 by Dr. Shapley, in his capacity of chairman of the American Section of the International Astronomical Union, after the Executive Committee of I.A.U. had given the project its endorsement at its March meeting in Copenhagen. At present, the membership of the Panel stands as follows:

S. Chandrasekhar, Yerkes Observatory,

C. M. Huffer, Washburn Observatory,

A. H. Joy, Mt. Wilson Observatory,

Zdeněk Kopal, Harvard Observatory,

G. E. Kron, Lick Observatory,

D. B. McLaughlin, University of Michigan Observatory,

J. E. Merrill, Hunter College,

C. H. Payne-Gaposchkin, Harvard Observa tory,

J. A. Pearce, Dominion Astrophysical Observatory, 